\title{
The Association of PM2.5 and Surface Ozone with Asthma Prevalence among School Children in Japan: 2006-2009
}

\author{
Amin Nawahda* \\ Environmental Research Center, Sohar University, Sohar, Oman; ${ }^{*}$ Corresponding Author: amin.nawahdah@gmail.com \\ Received 15 June 2013; revised 15 July 2013; accepted 2 August 2013 \\ Copyright (C) 2013 Amin Nawahda. This is an open access article distributed under the Creative Commons Attribution License, which \\ permits unrestricted use, distribution, and reproduction in any medium, provided the original work is properly cited.
}

\begin{abstract}
Researches on asthma have found that air pollution increased asthma prevalence among sensitive age groups, including school children, and exposed them to the recognized health impacts. The aim of this study is to examine the association between elevated annual mean concentration of PM2.5 (particulate matter with aerodynamic diameter less than 2.5 micrometers) and surface ozone and asthma prevalence among school children in Japan from 2006 to 2009. Annual rates of asthma prevalence among preschool and school children (5 to 11 years) are obtained from the database of the Ministry of Education, Culture, Sports, Science and Technology-Japan (MEXT). Data on the concentrations of PM2.5 and surface ozone were obtained from 1,183 stations of air quality monitoring distributed in 47 prefectures. Annual means of these concentrations were compared to annual variations in asthma prevalence by using Pearson correlation coefficient. We found different associations between the annual mean concentration of PM2.5 and surface ozone and the annual rates of asthma prevalence among preschool and school children from 2006 to 2009. The positive values of the correlation coefficient in prefectures such as, Gumma, Shimane, and Niigata, are consistent with the previous knowledge. However, significant inverse associations were found in many prefectures. Our study suggests that the association between elevated concentrations of PM2.5 and surface ozone and asthma prevalence among school children in Japan is not strong enough to assume concretely a plausible and significant association.
\end{abstract}

Keywords: Asthma; PM2.5; Ozone; School Children; Japan

\section{INTRODUCTION}

The environmental risks caused by exposure to elevated concentrations of PM2.5 and surface ozone have been increasing annually. The formed PM2.5 and surface ozone from pollution sources, which remain suspended for several hours and days and can travel long distances, endanger local and regional receptors, and expose human health to recognized adverse effects [1-6]. Asthma (International Classification of Disease $9^{\text {th }}$ revision, code 493; ICD9-493) is defined by the World Health Organization (WHO) as one of the chronic respiratory diseases that causes breathlessness and wheezing due to the inflammation of the air passages in the lungs and usually starts in early childhood. Asthma is not only related to genetic and environmental factors, but also it is believed to be affected by air pollutants such as PM2.5 and surface ozone. Asthma among adults and children has a long history in Japan and it was related to air pollution from mobile and stationary sources since 1964 [7-9]. Most of Japanese epidemiological studies were limited and based on short-term assessments of the association between air pollutants and asthma prevalence. Yamazaki et al., $[10,11]$ found that the odds ratio (OR) in warmer months per $10 \mathrm{ppb}$ increment in 24-hr mean concentration of surface ozone was 1.25 (95\% Confidence Interval (CI): $0.87-1.82$ ), and the association between ozone concentrations and asthma admissions for the preschool age group ( 2 - 5 years) was stronger than the age group of 6 14 years. Also, they found that correlating particulate maters with asthma admissions is not easy because they include different primary air pollutants. Ma et al., [12] found that the concentration of indoor particulate maters has more effects on asthma prevalence among the age 
group of $8-15$ years compared to outdoor concentration. Meteorological factors such as ambient temperature and relative humidity could affect asthma prevalence; however, they have no significant correlations and vary from person to person [13]. This study aimed to investigate the association of elevated mean annual concentration of PM2.5 and surface ozone in Japan and asthma prevalence among preschool and school children. The local atmosphere in Japan is affected by transboundary air pollutants that cause elevated concentrations in most of the prefectures on the Sea of Japan. Additionally, these prefectures have the highest asthma prevalence in Japan. According to the annual reports of Japan Ministry of Environment (MOEJ), the air quality standard of surface ozone concentration in Japan, 0.06 ppm 1-hour mean value, is usually exceeded in most of air quality monitoring stations there. During the period from 1974 to 2009, the mean annual concentration of SPM (suspended particulate matter with aerodynamic diameter less than 7.0 micrometers) decreased from 0.058 to $0.021 \mathrm{mgm}^{-3}$ in stationary monitors and from 0.162 to $0.024 \mathrm{mgm}^{-3}$ in mobile monitors (roadside monitor). In 2009, the air quality standards of SPM, $0.10 \mathrm{mgm}^{-3}$ daily average and $0.20 \mathrm{mgm}^{-3}$ hourly values, were met at more than $98.8 \%$ of the 1,792 monitors located throughout Japan [14].

\section{METHODOLOGY}

\subsection{Asthma Prevalence}

Sex-specific asthma prevalence records were obtained from the Ministry of Education, Culture, Sports, Science and Technology-Japan (MEXT) database, which is open to the public and contained health care data from all schools in Japan, for the period from 2006 to 2009 [15]. The study group involved two different age groups: preschool (5 years) and primary school (6 - 11 years).

\subsection{PM2.5 and Surface Ozone Data}

The mean annual concentrations of PM2.5 and surface ozone at each monitor from 2006 to 2009 are obtained from the National Institute of Environmental studies (NIES). These monitors are managed and operated by MOEJ and local governments. However, only few air quality monitors have both measurements of SPM and PM2.5, at these monitors the ratio of PM2.5 to SPM varied from 0.6 to 0.8 and could be affected by sampling method (filter collection, Anderson's sampler, light scattered estimation, and $\beta$-ray absorption) (Iwai et al., 2005). Accordingly, a conversion factor of 0.7 is assumed. This database includes 1,183 stations for air quality monitoring distributed in 47 prefectures in Japan (Figure 1 and Appendix A1). The monitored concentrations are; 24-hr mean, 1-hr daytime mean, and maximum-hr mean.

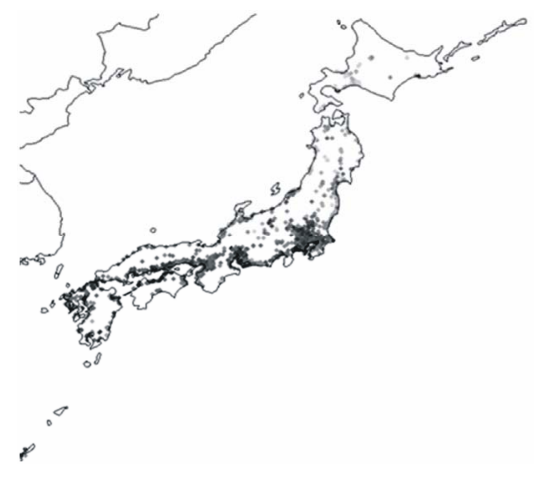

$\operatorname{SPM}\left(\mathrm{mg} / \mathrm{m}^{3}\right)$

$0.001-0.013$

$-0.014-0.018$

$\bullet 0.019-0.023$

$-0.024-0.028$

$\bullet 0.029-0.032$

$\bullet 0.033-0.038$

$\bullet 0.039-0.051$

Figure 1. Distributed air quality monitors of SPM and ozone in Japan, the map also shows the distribution of the mean annual concentrations of SPM in 2006.

\subsection{Statistical Analysis}

The association of annual variations of the asthma prevalence among preschool and school children, and elevated annual mean concentrations of PM2.5 and surface ozone was compared using the Pearson correlation coefficient (r) for the study period from 2006 to 2009. The annual mean concentrations were estimated by calculating the average of the annual mean concentrations of surface ozone from each station within its boundaries. The correlation coefficient was calculated based on both 1-hr daytime. Stata 8.2 [16] and Microsoft-Excel were used for the statistical analysis.

\section{RESULTS AND DISCUSSION}

The box plots in Figures 2(a) and (b) summarize the variations in the monitored SPM and surface ozone concentrations in Japan during the period from 2006 to 2009. The box plot in Figure 2(c) summarizes the variations in the registered asthma prevalence rates during the study period. Significant positive correlation coefficient was observed between the mean annual concentrations of PM2.5 and surface ozone (1-hr daytime mean values: $\mathrm{C} 1$, and maximum-hr mean values: $\mathrm{C} 2$ for ozone) and asthma prevalence among school children (age group 6 to 11 years: A2) during the 4-year study period as shown in Figures 3. The correlation coefficient (r) for all prefectures was 0.59 and 0.44 for $\mathrm{A} 2$ with $\mathrm{C} 1$ and $\mathrm{C} 2$, respectively. Among preschool children, A1, significant inverse correlation coefficient was observed, but weaker than the case of $\mathrm{A} 2$, the correlation coefficient (r) was -0.50 and -0.38 with $\mathrm{C} 1$ and $\mathrm{C} 2$, respectively.

In this study, we focused on the annual variations of SPM and surface ozone concentration and asthma prevalence for the following reasons: First, these secondary air pollutants are the best representative of air pollution in assessing the association with respiratory diseases [10]. Second, most of the available short-term studies in Japan showed contradicting results especially among preschool 


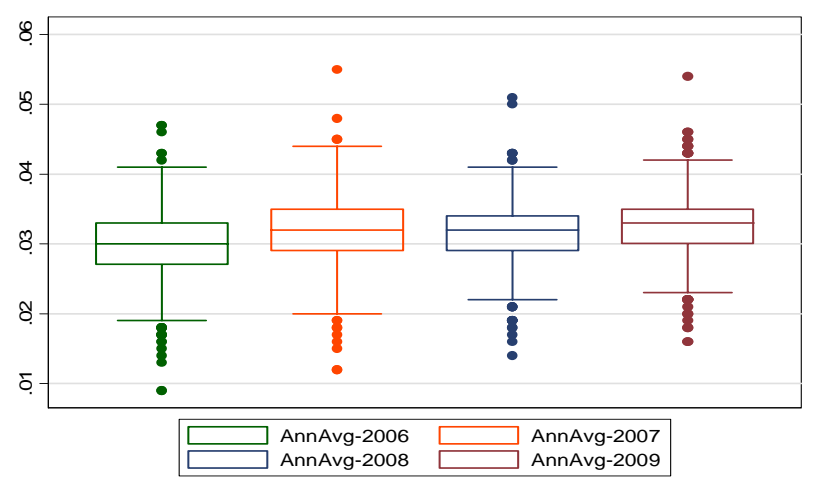

(a) Ozone (ppm)

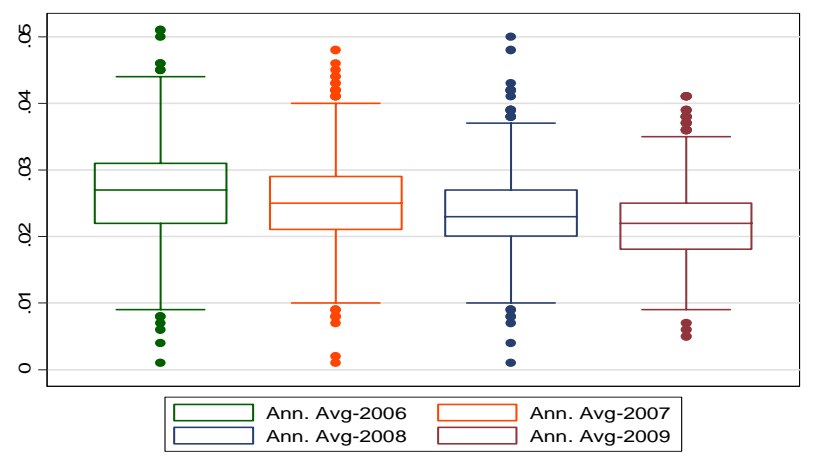

(b) SPM (mg/m³ $)$

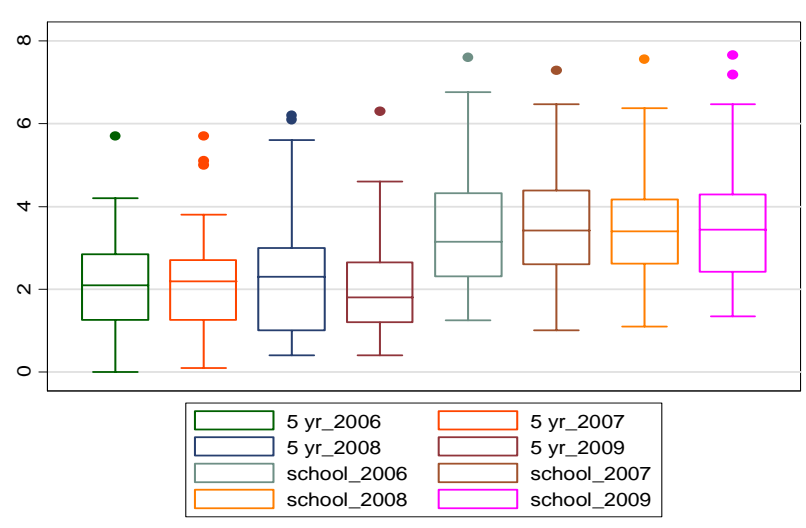

(c) Asthma prevalence (\%)

Figure 2. Annual variations of monitored surface ozone (a) and SPM (b), and annual variations for asthma prevalence in Japan (2006-2009) among two age groups 5 years and school children (6 - 11 years).

age group $[8,10-13,17,18$,$] . Third, data availability and$ less variation between indoor and outdoor concentrations compared to short term exposures. We found different association between the annual mean concentration of surface ozone, 1-hr daytime and maximum-hr mean values, and the annual asthma prevalence among preschool and school children, 5 to 11 years, in Japan during the 4-year study period. The positive values of the correlation coefficient in Figure 3, (e.g. Gunma (station no. 10), Shimane (station no. 20), and Niigata (station no. 15)), are consistent with hypotheses of the previous studies in Japan and consistent with the studies mentioned in the chapter of surface ozone in the WHO-Air Quality Guidelines (e.g. cohort of children with asthma in 12 southern California communities (odds ratio $=1.06$ per $2 \mu \mathrm{g} / \mathrm{m}^{3}$ ( 1 ppb), 95\% Confidence Interval: 1.00 1.12) (WHO, 2005, 2008). However, significant inverse associations were also found in many prefectures, (Figures 3 and 4), which is inconsistent with previous studies. Our study suggests that the long-term association between SPM and surface ozone and asthma prevalence among children in Japan is not clear enough to assume
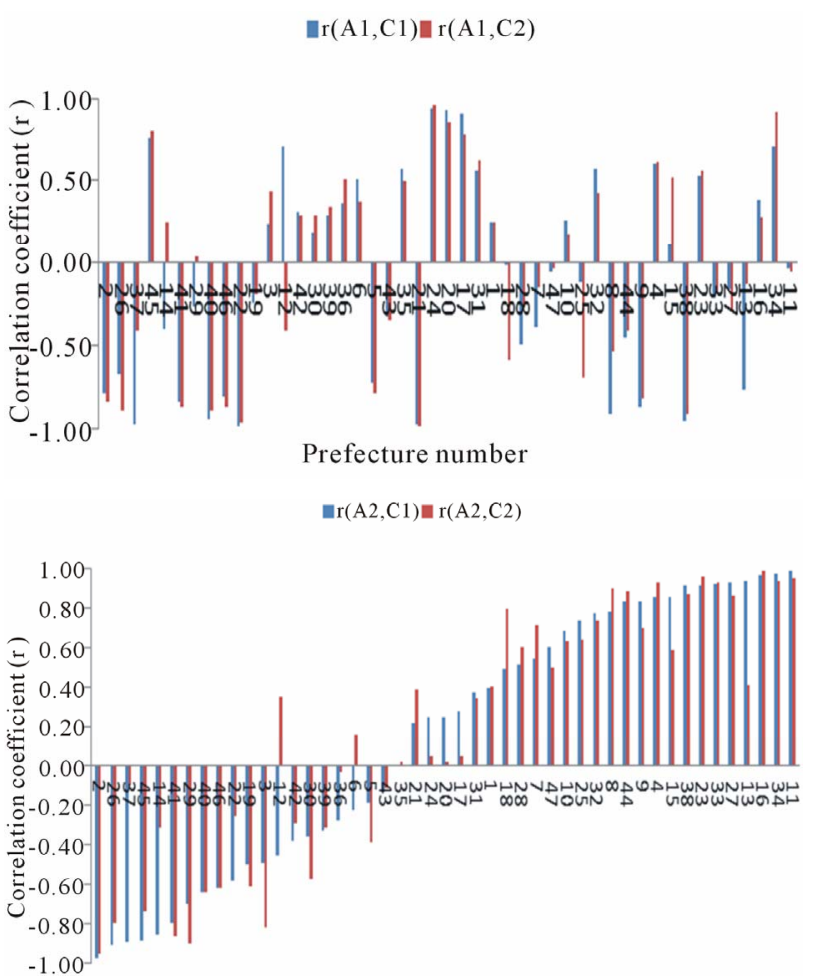

Figure 3. Correlation coefficient (r) between ozone concentrations $(\mathrm{C} 1$ and $\mathrm{C} 2)$ and asthma prevalence among preschool children (A1 in the upper figure) and school children (A2 in lower figure) (2006-2009).

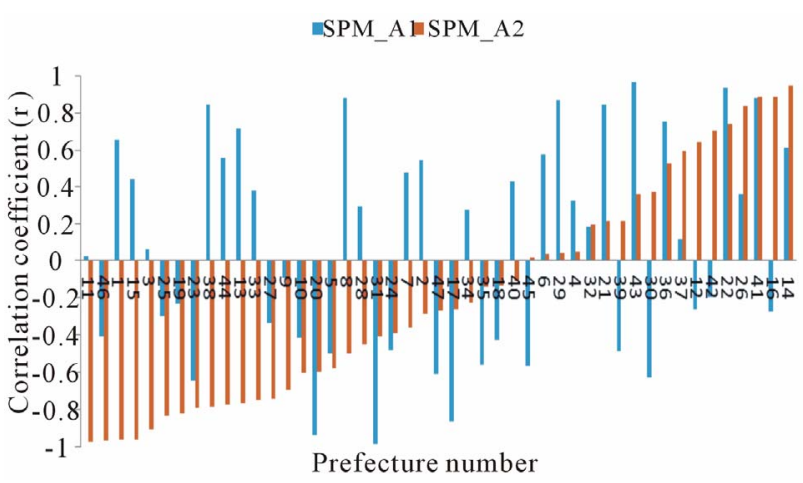

Figure 4. Correlation coefficient (r) between SPM mean annual concentration and asthma prevalence among preschool children (A1) and school children (A2) (2006-2009). 
concretely a plausible significant association. This is mainly because our findings show clear spatial variability of the correlation coefficient values. An explanation of this finding is that there is no statistical significant and recognized threshold level of surface ozone effect and SPM on the respiratory system. The reason for this is that human body has antioxidant defense system that differs from person to person (WHO, 2005).

The findings of this study could be conservative due to the uncertainty in the analysis. The uncertainty caused by ignoring seasonality of exposure and meteorological factors is not significant since asthma prevalence are yearly increasing since the past 30 years. The uncertainty caused by using $1-\mathrm{hr}$ daytime and maximum-hr mean concentrations instead of hourly data (24-hr data) in the analyses could overestimate the exposure, but insignificantly. To confirm this assumption we calculate the Pearson correlation coefficient between the 3 values for the year 2009 because this is the only official time series data by MOEJ that is opened to the public, the (r) value for correlating 24-hr concentrations with 1-hr daytime concentrations was 0.93 , the $(r)$ value for correlating 24-hr concentrations with maximum-hr concentration was 0.3 , and the (r) value for correlating 1-hr concentration with maximum-hr concentrations was 0.6. The uncertainty caused by co-existence of other pollutants also is insignificant because the annual reports of the MOEJ show clearly that air pollutants such as; NOx, SOx, aerosols, and NMHC (Non-Methanic Hydrocarbons, a precursor of surface ozone), are yearly decreasing since past 30 years. Additionally, we calculated the (r) values for correlating the annual asthma prevalence and the annual mean of the suspended particulate matters (SPM) in each prefecture (Appendix A2) as shown in Figure 4, the (r) values reflect different associations between elevated concentrations of SPM and asthma prevalence in Japan. However, there could be levels of uncertainty due to the difference between indoor and outdoor exposures. Exposure of school children to elevated concentrations of indoor air pollutants in Japan is not common because of the healthy environment inside schools. Another possible source of uncertainty could be the wrong diagnosis of asthma prevalence.

\section{CONCLUSION}

The present study adds limited evidence to the widely assumed hypothesis of a significant association between SPM and surface ozone and asthma prevalence among preschool and school children. This hypothesis was found to be valid only for few prefectures in Japan. The lack of significant association in many prefectures in places where elevated concentrations of surface ozone and SPM were observed requires further research. Addi- tionally, the findings of this study about the effects of air pollution on human health in Japan based on Western epidemiological studies show that these effects should be carefully estimated and our estimations of the health effects in previous studies $[19,20]$ should be reexamined based on Japanese epidemiological studies once available.

\section{ACKNOWLEDGEMENTS}

The author thanks Allah, Family, the staff of the National Institute of Public Health (NIPH) and Dr. Oba for their assistant. Also, thanks the Asia Center for Air Pollution Research (ACAP) for their support and cooperation and the Research Council in Oman (TRC) for their support.

\section{REFERENCES}

[1] US-EPA (2006) Ozone health risk assessment for selected urban areas.

http://www.epa.gov/ttnnaaqs/standards/ozone/data/ozone ra_2nd_draft_tsd_mainbody_7-18-2006.pdf

[2] Lippmann, M. (2009) Environmental toxicants/human exposures and their effects. John Wiley \& Sons Inc., New Jersey, 317-359.

http://dx.doi.org/10.1002/9780470442890.ch10

[3] Anenberg, S.C., Horowitz, L.W., Tong, D.Q. and West, J. (2010) An estimation of the global burden of anthropogenic ozone and fine particulate matter on premature human mortality using atmospheric modeling. Environmental Health Perspectives, 18, 1189-1195.

http://dx.doi.org/10.1289/ehp.0901220

[4] Mauzerall, D.L., Sultan, B., Kim, N. and Bradford, D.F. (2005) NOx emissions from large point sources: Variability in ozone production, resulting health damages and economic costs. Atmospheric Environment, 39, 2851-2866. http://dx.doi.org/10.1016/j.atmosenv.2004.12.041

[5] WHO (2008) Health risks of ozone from long-range transboundary air pollution. WHO Regional Office for Europe, Copenhagen.

[6] WHO (2005) Air quality guidelines for particulate matters, ozone, nitrogen dioxide/global update/summary of risk assessment.

http://whqlibdoc.who.int/hq/2006/WHO_SDE_PHE_OE H_06.02_eng.pdf

[7] Motley, H.L. and Phelps, H.W. (1964) Pulmonary function impairment produced by atmospheric pollution. Chest, 45, 154-162. http://dx.doi.org/10.1378/chest.45.2.154

[8] Guo, P., Yokoyama, K., Suenaga, M. and Kida, H. (2008) Mortality and life expectancy of Yokkaichi asthma patients, Japan: Late effects of air pollution in 1960-70s. Environmental Health, 26, 8 .

[9] Kagawa, J. (1994) Atmospheric pollution due to mobile sources and effects on human health in Japan. Environmental Health Perspectives, 102, 93-99.

[10] Yamazaki, S., Shima, M., Ando, M. and Nitta, H. (2009) Modifying effect of age on the association between ambient ozone and nighttime primary care visits due to asth- 
ma attack. Journal of Epidemiology, 19, 143-151. http://dx.doi.org/10.2188/jea.JE20081025

[11] Yamazaki, S., Shima, M., Ando, M., Nitta, H., Watanabe, H. and Nishimuta, T. (2011) Effect of hourly concentration of particulate matter on peak expiratory flow in hospitalized children: A panel study. Environmental Health, 10, 15.

[12] Ma, L., Shima, M., Yoda, Y., Yamamoto, H., Nakai, S., Tamura, K., Nitta, H., Watanabe, H. and Nishimuta, T. (2008) Effects of airborne particulate matter on respiratory morbidity in asthmatic children. Journal of Epidemiology, 8, 97-110. http://dx.doi.org/10.2188/jea.JE2007432

[13] Tanaka, H., Honma, S., Nishi, M., Igarashi, T., Nishio, F. and Abe, S. (1996) Two-year follow-up study of the effect of acid fog on adult asthma patients. Internal Medicine, 35, 100-104. http://dx.doi.org/10.2169/internalmedicine.35.100

[14] MOEJ (2009) 21 JFY air quality monitoring report (in Japanese). http://www.env.go.jp/en/

[15] MEXT (2011) Survey of school health (in Japanese/ English).
http://www.e-stat.go.jp/SG1/estat/NewList.do?tid=00000 $\underline{1011648}$

[16] Stata Statistical Software (2005) Release 8.2 stata Corp, LP.

[17] Shima, M., Nitta, Y. and Adachi, M. (2003) Trafficrelated air pollution and respiratory symptoms in children living along trunk roads in Chiba Prefecture, Japan. Journal of Epidemiology, 3, 108-119. http://dx.doi.org/10.2188/jea.13.108

[18] Shima, M. and Adachi, M. (1998) Indoor nitrogen dioxide in homes along trunk roads with heavy traffic. Occupational and Environmental Medicine, 55, 428-433.

[19] Nawahda, A. (2013) Reductions of $\mathrm{PM}_{2.5}$ air concentrations and possible effects on premature mortality in Japan. Water, Air, \& Soil Pollution, 224, 1508.

[20] Nawahda, A., Yamashita, K., Ohara, T., Kurokawa, J. and Yamaji, K. (2012) Evaluation of premature mortality caused by exposure to $\mathrm{PM}_{2.5}$ and ozone in East Asia: 2000, 2005, 2020. Water, Air, \& Soil Pollution, 223, 3445-3459. 


\section{Appendix A1:}

Table A1. List of the 47 prefectures in Japan, ozone concentrations, and asthma prevalence rates from 2006 to 2009.

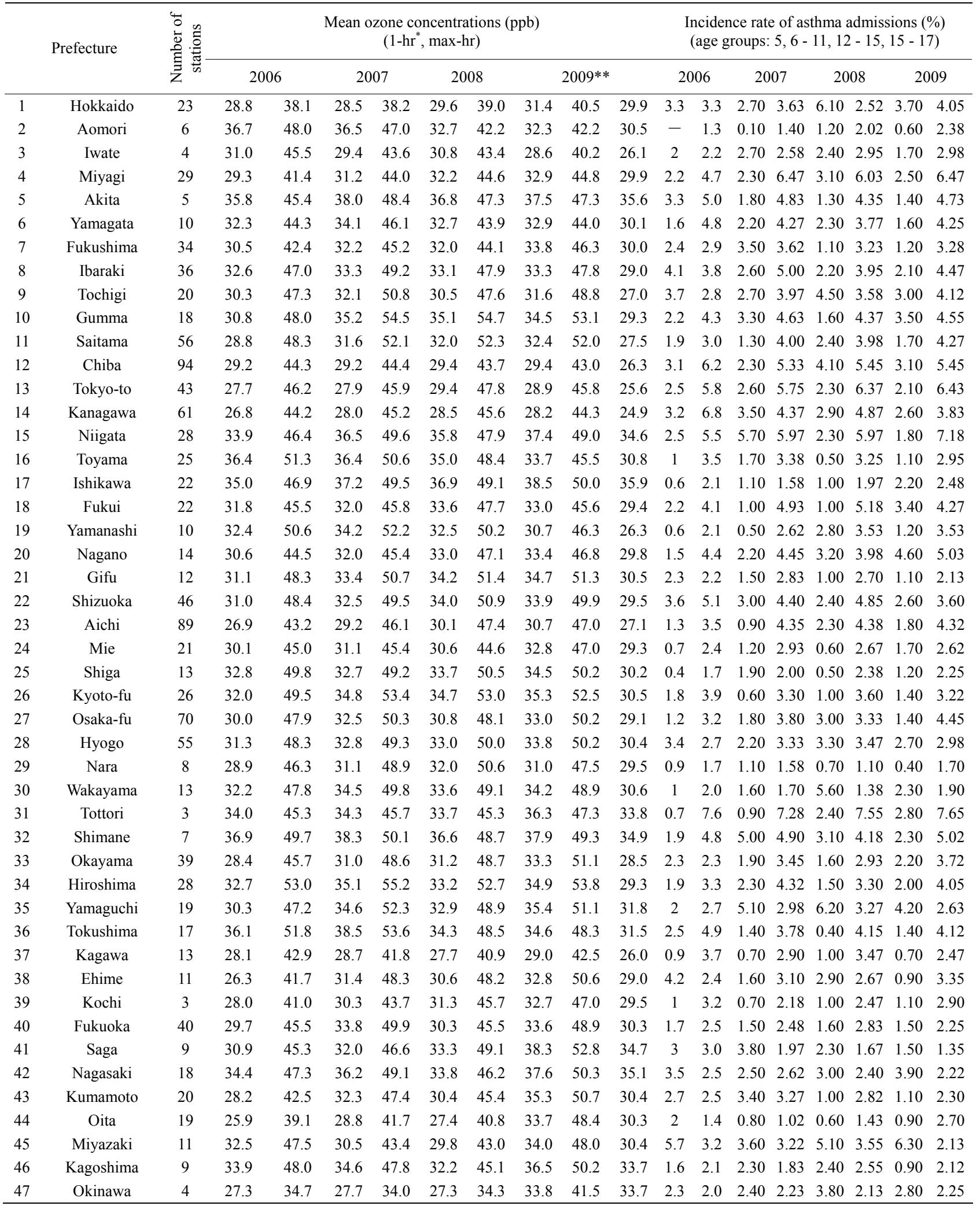

"hourly mean concentration during daytime; ${ }^{* *}$ the third value is the 24 -hr mean concentration. 
Appendix A2:

Table A2. List of the 47 prefectures in Japan, SPM annual concentrations, and asthma prevalence rates from 2006 to 2009.

\begin{tabular}{|c|c|c|c|c|c|c|c|c|c|c|c|c|c|c|c|}
\hline \multirow{2}{*}{ Pref. } & \multirow{2}{*}{ 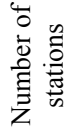 } & \multicolumn{4}{|c|}{$\mathrm{SPM}\left(\mathrm{mg} / \mathrm{m}^{3}\right)$} & \multicolumn{8}{|c|}{ Asthma prevalence } & \multirow{2}{*}{$\begin{array}{c}\mathrm{R} \\
\mathrm{A} 1\end{array}$} & \multirow{2}{*}{$\begin{array}{c}\mathrm{R} \\
\mathrm{A} 2\end{array}$} \\
\hline & & 2006 & 2007 & 2008 & 2009 & $\begin{array}{c}2006 \\
\text { A1 }\end{array}$ & $\begin{array}{c}2007 \\
\text { A1 }\end{array}$ & $\begin{array}{c}2008 \\
\text { A1 }\end{array}$ & $\begin{array}{c}2009 \\
\text { A1 }\end{array}$ & $\begin{array}{c}2006 \\
\text { A2 }\end{array}$ & $\begin{array}{c}2007 \\
\text { A2 }\end{array}$ & $\begin{array}{c}2008 \\
\text { A2 }\end{array}$ & $\begin{array}{c}2009 \\
\text { A2 }\end{array}$ & & \\
\hline Hokkaido & 84 & 0.014 & 0.014 & 0.015 & 0.013 & 3.3 & 2.7 & 6.1 & 3.7 & 3.3 & 3.63 & 2.52 & 4.05 & 0.66 & -0.96 \\
\hline Aomori-ken & 20 & 0.017 & 0.017 & 0.018 & 0.016 & - & 0.1 & 1.2 & 0.6 & 1.3 & 1.4 & 2.02 & 2.38 & 0.54 & -0.29 \\
\hline Iwate-ken & 11 & 0.017 & 0.015 & 0.015 & 0.014 & 2 & 2.7 & 2.4 & 1.7 & 2.2 & 2.58 & 2.95 & 2.98 & 0.06 & -0.91 \\
\hline Miyagi-ken & 41 & 0.02 & 0.021 & 0.021 & 0.019 & 2.2 & 2.3 & 3.1 & 2.5 & 4.7 & 6.47 & 6.03 & 6.47 & 0.32 & 0.05 \\
\hline Akita-ken & 22 & 0.015 & 0.016 & 0.016 & 0.015 & 3.3 & 1.8 & 1.3 & 1.4 & 5 & 4.83 & 4.35 & 4.73 & -0.50 & -0.58 \\
\hline Yamagata-ken & 16 & 0.016 & 0.016 & 0.016 & 0.015 & 1.6 & 2.2 & 2.3 & 1.6 & 4.8 & 4.27 & 3.77 & 4.25 & 0.57 & 0.04 \\
\hline Fukushima-ken & 29 & 0.019 & 0.018 & 0.018 & 0.016 & 2.4 & 3.5 & 1.1 & 1.2 & 2.9 & 3.62 & 3.23 & 3.28 & 0.48 & -0.36 \\
\hline Ibaraki-ken & 51 & 0.024 & 0.022 & 0.022 & 0.02 & 4.1 & 2.6 & 2.2 & 2.1 & 3.8 & 5 & 3.95 & 4.47 & 0.88 & -0.50 \\
\hline Tochigi-ken & 36 & 0.027 & 0.026 & 0.024 & 0.023 & 3.7 & 2.7 & 4.5 & 3 & 2.8 & 3.97 & 3.58 & 4.12 & -0.09 & -0.70 \\
\hline Gumma-ken & 32 & 0.028 & 0.024 & 0.023 & 0.021 & 2.2 & 3.3 & 1.6 & 3.5 & 4.3 & 4.63 & 4.37 & 4.55 & -0.41 & -0.60 \\
\hline Saitama-ken & 80 & 0.031 & 0.027 & 0.026 & 0.024 & 1.9 & 1.3 & 2.4 & 1.7 & 3 & 4 & 3.98 & 4.27 & 0.02 & -0.97 \\
\hline Chiba-ken & 142 & 0.029 & 0.027 & 0.025 & 0.022 & 3.1 & 2.3 & 4.1 & 3.1 & 6.2 & 5.33 & 5.45 & 5.45 & -0.27 & 0.64 \\
\hline Tokyo-to & 86 & 0.031 & 0.027 & 0.026 & 0.024 & 2.5 & 2.6 & 2.3 & 2.1 & 5.8 & 5.75 & 6.37 & 6.43 & 0.71 & -0.77 \\
\hline Kanagawa-ken & 93 & 0.031 & 0.027 & 0.026 & 0.024 & 3.2 & 3.5 & 2.9 & 2.6 & 6.8 & 4.37 & 4.87 & 3.83 & 0.61 & 0.95 \\
\hline Niigata-ken & 34 & 0.023 & 0.022 & 0.021 & 0.019 & 2.5 & 5.7 & 2.3 & 1.8 & 5.5 & 5.97 & 5.97 & 7.18 & 0.44 & -0.96 \\
\hline Toyama-ken & 31 & 0.021 & 0.018 & 0.019 & 0.016 & 1 & 1.7 & 0.5 & 1.1 & 3.5 & 3.38 & 3.25 & 2.95 & -0.28 & 0.89 \\
\hline Ishikawa-ken & 24 & 0.02 & 0.018 & 0.02 & 0.017 & 0.6 & 1.1 & 1 & 2.2 & 2.1 & 1.58 & 1.97 & 2.48 & -0.87 & -0.26 \\
\hline Fukui-ken & 35 & 0.022 & 0.02 & 0.02 & 0.018 & 2.2 & 1 & 1 & 3.4 & 4.1 & 4.93 & 5.18 & 4.27 & -0.43 & -0.13 \\
\hline Yamanashi-ken & 12 & 0.023 & 0.02 & 0.02 & 0.017 & 0.6 & 0.5 & 2.8 & 1.2 & 2.1 & 2.62 & 3.53 & 3.53 & -0.23 & -0.82 \\
\hline Nagano-ken & 23 & 0.021 & 0.02 & 0.02 & 0.019 & 1.5 & 2.2 & 3.2 & 4.6 & 4.4 & 4.45 & 3.98 & 5.03 & -0.94 & -0.60 \\
\hline Gifu-ken & 20 & 0.025 & 0.023 & 0.021 & 0.018 & 2.3 & 1.5 & 1 & 1.1 & 2.2 & 2.83 & 2.7 & 2.13 & 0.85 & 0.21 \\
\hline Shizuoka-ken & 61 & 0.027 & 0.023 & 0.022 & 0.021 & 3.6 & 3 & 2.4 & 2.6 & 5.1 & 4.4 & 4.85 & 3.6 & 0.93 & 0.74 \\
\hline Aichi-ken & 141 & 0.032 & 0.029 & 0.026 & 0.024 & 1.3 & 0.9 & 2.3 & 1.8 & 3.5 & 4.35 & 4.38 & 4.32 & -0.65 & -0.79 \\
\hline Mie-ken & 31 & 0.028 & 0.024 & 0.021 & 0.02 & 0.7 & 1.2 & 0.6 & 1.7 & 2.4 & 2.93 & 2.67 & 2.62 & -0.49 & -0.39 \\
\hline Shiga-ken & 13 & 0.026 & 0.024 & 0.023 & 0.021 & 0.4 & 1.9 & 0.5 & 1.2 & 1.7 & 2 & 2.38 & 2.25 & -0.30 & -0.84 \\
\hline Kyoto-fu & 34 & 0.026 & 0.023 & 0.022 & 0.02 & 1.8 & 0.6 & 1 & 1.4 & 3.9 & 3.3 & 3.6 & 3.22 & 0.36 & 0.84 \\
\hline Osaka-fu & 104 & 0.031 & 0.028 & 0.026 & 0.024 & 1.2 & 1.8 & 3 & 1.4 & 3.2 & 3.8 & 3.33 & 4.45 & -0.34 & -0.75 \\
\hline Hyogo-ken & 97 & 0.029 & 0.026 & 0.024 & 0.022 & 3.4 & 2.2 & 3.3 & 2.7 & 2.7 & 3.33 & 3.47 & 2.98 & 0.30 & -0.45 \\
\hline Nara-ken & 14 & 0.028 & 0.027 & 0.026 & 0.024 & 0.9 & 1.1 & 0.7 & 0.4 & 1.7 & 1.58 & 1.1 & 1.7 & 0.87 & 0.04 \\
\hline Wakayama-ken & 32 & 0.025 & 0.024 & 0.021 & 0.02 & 1 & 1.6 & 5.6 & 2.3 & 2 & 1.7 & 1.38 & 1.9 & -0.63 & 0.37 \\
\hline Tottori-ken & 5 & 0.021 & 0.02 & 0.018 & 0.017 & 0.7 & 0.9 & 2.4 & 2.8 & 7.6 & 7.28 & 7.55 & 7.65 & -0.99 & -0.41 \\
\hline Shimane-ken & 9 & 0.025 & 0.024 & 0.021 & 0.02 & 1.9 & 5 & 3.1 & 2.3 & 4.8 & 4.9 & 4.18 & 5.02 & 0.19 & 0.20 \\
\hline Okayama-ken & 59 & 0.03 & 0.028 & 0.026 & 0.025 & 2.3 & 1.9 & 1.6 & 2.2 & 2.3 & 3.45 & 2.93 & 3.72 & 0.38 & -0.75 \\
\hline Hiroshima-ken & 39 & 0.032 & 0.03 & 0.027 & 0.025 & 1.9 & 2.3 & 1.5 & 2 & 3.3 & 4.32 & 3.3 & 4.05 & 0.28 & -0.22 \\
\hline Yamaguchi-ken & 34 & 0.027 & 0.026 & 0.022 & 0.021 & 2 & 5.1 & 6.2 & 4.2 & 2.7 & 2.98 & 3.27 & 2.63 & -0.56 & -0.14 \\
\hline Tokushima-ken & 22 & 0.027 & 0.025 & 0.022 & 0.021 & 2.5 & 1.4 & 0.4 & 1.4 & 4.9 & 3.78 & 4.15 & 4.12 & 0.75 & 0.53 \\
\hline Kagawa-ken & 21 & 0.031 & 0.028 & 0.026 & 0.026 & 0.9 & 0.7 & 1 & 0.7 & 3.7 & 2.9 & 3.47 & 2.47 & 0.12 & 0.60 \\
\hline Ehime-ken & 26 & 0.032 & 0.028 & 0.027 & 0.026 & 4.2 & 1.6 & 2.9 & 0.9 & 2.4 & 3.1 & 2.67 & 3.35 & 0.84 & -0.79 \\
\hline Kochi-ken & 6 & 0.025 & 0.023 & 0.018 & 0.018 & 1 & 0.7 & 1 & 1.1 & 3.2 & 2.18 & 2.47 & 2.9 & -0.49 & 0.22 \\
\hline Fukuoka-ken & 58 & 0.032 & 0.031 & 0.027 & 0.027 & 1.7 & 1.5 & 1.6 & 1.5 & 2.5 & 2.48 & 2.83 & 2.25 & 0.43 & -0.11 \\
\hline Saga-ken & 16 & 0.027 & 0.026 & 0.023 & 0.021 & 3 & 3.8 & 2.3 & 1.5 & 3 & 1.97 & 1.67 & 1.35 & 0.88 & 0.88 \\
\hline Nagasaki-ken & 23 & 0.03 & 0.029 & 0.025 & 0.026 & 3.5 & 2.5 & 3 & 3.9 & 2.5 & 2.62 & 2.4 & 2.22 & -0.20 & 0.70 \\
\hline Kumamoto-ken & 30 & 0.027 & 0.027 & 0.022 & 0.023 & 2.7 & 3.4 & 1 & 1.1 & 2.5 & 3.27 & 2.82 & 2.3 & 0.96 & 0.36 \\
\hline Oita-ken & 24 & 0.026 & 0.026 & 0.022 & 0.021 & 2 & 0.8 & 0.6 & 0.9 & 1.4 & 1.02 & 1.43 & 2.7 & 0.56 & -0.78 \\
\hline Miyazaki-ken & 15 & 0.026 & 0.027 & 0.024 & 0.025 & 5.7 & 3.6 & 5.1 & 6.3 & 3.2 & 3.22 & 3.55 & 2.13 & -0.57 & 0.02 \\
\hline Kagoshima-ken & 17 & 0.028 & 0.029 & 0.024 & 0.028 & 1.6 & 2.3 & 2.4 & 0.9 & 2.1 & 1.83 & 2.55 & 2.12 & -0.41 & -0.97 \\
\hline Okinawa-ken & 9 & 0.024 & 0.025 & 0.022 & 0.021 & 2.3 & 2.4 & 3.8 & 2.8 & 2 & 2.23 & 2.13 & 2.25 & -0.61 & -0.27 \\
\hline
\end{tabular}

